\title{
The Influence of Health Education How to Care for Teeth and Mouths on Knowledge, Attitude and Skills and the Status of Dental and Oral Health in Elementary School
}

\author{
Santun Setiawati*, Nurdiana Siahaan, Yupi Supartini, Yenny Sianturi \\ Polytechnic Ministry of Health Jakarta 111 \\ Jl. Arteri JORR, Jati Warna, Indonesia \\ ${ }^{*}$ Corresponding author's email: santun2312 [AT] gmail.com
}

\begin{abstract}
One health problem that often occurs in school-age children is dental and oral health problems. One of the efforts made by increasing the knowledge of children and parents about dental and oral health. This study aims to determine the effect of health education on how to care for teeth and mouth on knowledge, attitudes and skills as well as dental and oral health status in elementary school children. This study uses a quasi-experimental design. Respondents of the study amounted to 64 children (intervention group 32 children and control group 32 children). In the intervention group health education was carried out on how to care for teeth and mouth and observed ways to care for teeth and mouth at home for 1 month by involving parents and being monitored by the teacher, while the control group was not carried out. Test the analysis using bivariate univariate (frequency distribution) analysis ( $t$ test and correlation test) and multivariate (multiple linear regression). The results showed that there was an effect of health education on how to care for teeth and mouth on the knowledge, attitudes and skills and dental and oral health status of elementary school children ( $p$ value $=0.000-0.002$ and $\alpha=0.0050$ ). Conclusion: health education about how to care for teeth and mouth is an effort to improve dental and oral health status in children.
\end{abstract}

Keywords - health education, school children, teeth and mouth.

\section{INTRODUCTION}

Children are someone who is not yet 18 years old including children who are still in the womb (Child Protection Act, 2014). Children go through the stages of growth and development starting from the womb, the age of the baby, toddler age, preschool age, school age and adolescence. School-age children are strategic targets for the implementation of health programs because they have a large number $(25 \%)$ of the population and are easily accessible because they are well organized [1]

The prevalence of dental and oral health problems were $21.6 \%$ which occurred in children aged 5-9 years and $20.6 \%$ in children aged 10-14 years. Active dental caries occur in children aged 12 years is $29.8 \%$ and children over the age of 12 are $43.9 \%$ while children aged 12 years with dental caries experience are $36.1 \%$ and children over the age of 12 years are $72.1 \%$. [2] Caries dentist experience for children over 12 years increased to $72.6 \%$ and active caries aged 12 years increased to $53.7 \%$. About $73.6 \%$ of 12 -year-olds need dental filling, but $3.2 \%$ of new fillings have been done School age, especially in elementary school grade 1, grade 2 or grade 3 is the most important period because at this time is the beginning of the transition between the date of the teeth and the start of the growth of permanent teeth. Dental health education is often overlooked both at home and at school, because there are still many parents who understand that milk teeth do not need treatment.[2] At this time it is very important to provide health education related to dental and oral health involving parents and teachers at school. Students are expected to understand the importance of dental and oral hygiene, and want to implement it and be able to practice it every day so that dental and oral hygiene can be achieved from an early age. Understanding of dental and oral health is needed in children by giving proper explanation of how to clean teeth and mouth and children want to do it and are able to practice how to clean teeth and mouth properly. Health education about dental and oral hygiene using attractive media so that it is easy to understand by children. Introducing the world of health to children in school, it should not be too difficult; The impact of dental caries experienced by children includes a smelly mouth that will cause a feeling of lack of confidence, causing growth disturbances due to pain caused especially when eating so that children become appetite. The pain caused can inhibit student achievement in school because children are not present at school following learning activities due to toothache. that there is a significant increase in health knowledge about teeth and mouth with power point and flipchart media [4] the use of toothpaste 
containing herbs and without herbs has the same effectiveness in decreasing plaque index in teeth[5] eating and drinking cariogenic foods caused dental caries[6] oral and dental hygiene would improve dental and oral health status [7] Understanding of dental and oral health is needed in children by giving proper explanation of how to clean teeth and mouth and children want to do it and are able to practice how to clean teeth and mouth properly. Health education about dental and oral hygiene using attractive media so that it is easy to understand by children.

\section{RESEARCH METHOD}

The research design was carried out with quasi experiments. In the child intervention group health education was conducted on how to care for teeth and mouth while in the control group there was no health education The time for the study began in February to December 2017. The study was conducted at SDN 01 Bambu Apus, East Jakarta (intervention group) and at SDN 02 Bambu Apus, East Jakarta (control group) working area of the Cipayung District Health Center, East Jakarta.

The sample in this study were school-aged children who were in grade 3 elementary school, with inclusion criteria: grade 3 elementary school children; the child is able to read; the child is able to write and the child and parents / family are willing to become respondents. The exclusion criteria are: children less than 7 years old and more than 12 years old; children who do not understand filling out the questionnaire given; parents who disagree with their children are included in the study. Sampling in this study with a random technique with consecutive sampling type. The number of samples in this study was calculated using unpaired numerical analysis. The total sample is 64 children. Data collection techniques were carried out: students filled out the questionnaire (pretest); students have dental and oral health checks; researchers carry out health education to students and parents about how to care for teeth and mouth; students practice how to care for teeth and mouth; students were observed while caring for their teeth and mouth by parents for 1 month at home and monitored by the teacher; students refill the questionnaire sheet (posttest); students have dental and oral health checks (after 1 month of dental and oral care); parents observe students while caring for their teeth and mouth at home. The questionnaire used was the result of modification carried out by researchers from health screening technical guidelines and periodic checks on primary and secondary education units issued by the Ministry of Health.

\section{RESULT}

The results of the analysis showed that the proportion of the age of the most respondents in the intervention group was 8 years as many as 18 people, while in the control group was 9 years as many as 26 people. The highest proportion of respondents in the intervention group were women, namely 20 people $(62.5 \%)$ and in the control group were men, namely 18 people $(56.2 \%)$. The education level of the majority of respondents is high school.

Characteristics of Knowledge, Attitudes and Skills

Prior to the intervention the highest average knowledge in the intervention group (3.25); the highest attitude in the intervention group (2.16) and the highest skill in the control group (2.81) (Table 5). After intervention the highest average knowledge in the intervention group (5.28); highest attitude in the intervention group (2.84) and highest skill in the intervention group (3.72) Characteristics of Dental and Oral Health

Before the average intervention: highest dental health in the intervention group (3.13); highest oral health in the control group (4.53) After an average intervention: highest dental health in the intervention group (3.69); highest oral health in the control group (4.81)

The results of bivariate analysis showed that there were significant differences in the knowledge, attitudes and skills of respondents in the intervention group ( $p$ value $=0.000$ and $\alpha=0.05$ ). There are significant differences in the attitudes and skills of respondents in the control group ( $p$ value $=0.000$ and $\alpha=0.05$ ) (Table 9). The results of the analysis showed that there were significant differences in dental and oral health status in the intervention group ( $\mathrm{p}$ value $=0.002$ and 0.000 with $\alpha=0.05$ ). There were significant differences in oral health status in the control group ( $\mathrm{p}$ value $=0.037$ and $\alpha=0.05$ )

Multivariate Analysis result, Before conducting a multivariate analysis, bivariate selection was carried out related to factors that influence changes in knowledge, attitudes and skills as well as dental and oral health status. Bivariate selection analysis using correlation test and test. The results of the analysis showed that there was a significant relationship between age and sex with knowledge, attitudes, skills and dental health. Then a multivariate analysis was performed with a value of $\mathrm{p}<0.25$. The results of the analysis show that age factors influence changes in knowledge (p value $=0.000)$; attitude $(\mathrm{p}$ value $=0.043)$ and oral health $(\mathrm{p}$ value $=0, .033)$ and gender affect skills changes $(\mathrm{p}$ value $=$ 0.040 ) about dental and oral health at $\alpha=0.05$.

\section{DISCUSSION}

Characteristics of Respondents. , Respondents in this study were elementary school children in grade 3 both in the intervention group and in the control group. The highest age of respondents is 9 years old (63\%). Respondents attend 
schools with the same characteristics, namely public elementary schools in the same area and close together. All students can read well so it's easy when filling out the questionnaire and cooperating. This makes it easy for the data analysis process. Age has an influence on the capture power and mindset of a person. As you get older, you will also develop the ability to catch and think [8] The most respondents in this study, both in the intervention group and in the control group were 34 women (53\%). But all students, both male and female, can work together well and cooperatively during research. Gender differences, both male and female sex do not significantly influence the level of knowledge and attitudes of students after being given counseling.[11] Although the differences in attention given by respondents during counseling, where female students were more attentive than male students during counseling. The gender differences in respondents did not affect the level of respondents' knowledge and attitude. The majority of respondents respond to high school education as many as 26 people (81\%). High school education is expected to be able to work well together especially related to children's health, especially dental and oral health. The level of education is related to the level of knowledge. The higher the education, the smaller the risk of dental caries [9] Mother's knowledge about dental and oral health is related to the dental and oral health status of primary school children [10]. Characteristics of Knowledge, Attitudes and Skills about Dental and Oral Hygiene

This study involved third grade elementary school respondents. The number of respondents in the intervention group was 32 people and in the control group 32 people. In the intervention group there was a significant difference between knowledge before and after the intervention ( $\mathrm{p}$ value $=0.000$ and $\alpha=0.05$ ). Changes in knowledge value occur with the difference between knowledge before and after treatment is 2.03. Changes in the value of knowledge are supported by the implementation of health education on how to care for teeth and mouth. The implementation of health education involves the parents of respondents. All parents invited are present. Implementation of health education with PPT media, LCDs, dental props and toothbrushes and videos on how to care for teeth and mouth. Health education activities are facilitated by homeroom teachers and principals. All parents approve their children to be included in the study. The approval process was preceded by an informed consent study. The use of attractive media can also increase knowledge about dental and oral health [11] Attitude assessment in the intervention group had a significant difference between attitudes before and after the intervention ( $p$ value $=0.000$ and $\alpha=0.05$ ). Changes in attitude values occur with the difference between the attitudes before and after treatment is 0.68. Changes in attitude that occur because students get health education how to care for teeth and mouth. Parents are also involved when providing health education and accompanying children while caring for their teeth and mouth for 1 month at home. Class teachers also play an active role by asking students about the implementation of dental and oral care carried out at home. Parental involvement in developing positive behavioral patterns in dental and oral health care is implemented in their children in daily life both directly and indirectly.[10]

In the control group there was a significant difference between the attitude values before and after the intervention ( $p$ value $=0.000$ and $\alpha=0.05)$. The difference in the value of attitude before and after treatment is 0.47 . Students in the control group did not do health education on how to care for their teeth and mouth, but the distance of the adjacent school allowed students to communicate with each other. Adjacent school distance also allows teachers and principals to communicate with each other regarding the implementation of the research conducted. Students can also get information about how to care for teeth and mouth from electronic media, teachers at school and parents at home. Skill assessment in the intervention group had a significant difference between the skills before and after the intervention $(\mathrm{p}$ value $=0.000$ and $\alpha=0.05)$. Changes in the skill value with the difference between the skill value before and after treatment is 1.19 . Changes in skills values because students have received health education how to care for teeth and mouth. Video screening of how to care for teeth and mouth helps students better understand how to care for teeth and mouth properly. A good media should be able to adjust the characteristics of the audience so that what is conveyed can be received effectively [11]

In the control group there was a significant difference between the skill scores before and after the intervention (p value $=0.000$ and $\alpha=0.05$ ). Skill difference before and after treatment is 0.85 . Students can also get information about how to care for teeth and mouth from television, read health books or magazines, teachers at school, parents at home or playmates.

Characteristics of Dental and Oral Health

The results of dental health examinations in the intervention group had a significant difference between dental health examinations before and after the intervention ( $\mathrm{p}$ value $=0.002$ and $\alpha=0.05$ ). There was a change in the condition of the results of dental health examination with the difference between the dental health check before and after treatment was 0.56. The results of dental and oral health examinations are conveyed to parents. Parents respond well. Some parents have taken students to health services to be examined, have their teeth patched, teeth removed and dental treatment. The child is also not afraid when taken to the community health center for dental and oral examinations by the dentist. The better the cleanliness of the teeth and mouth of students, the better their dental health status will be [7].

One factor that is directly related to the process of caries is dental and oral hygiene. The habit of brushing teeth can also affect the severity of caries, respondents who brush their teeth have a tendency to have caries lighter than those who do not brush their teeth [9]. One of the factors that causes low dental and oral hygiene in school children is poor tooth brushing behavior. The most important effort to prevent or reduce plaque formation is brushing teeth. The search for dental treatment for health workers needs to be improved through increasing information, knowledge and one's 
perception about dental and oral health. Formation of behavior patterns requires the role of others such as parents, friends, school environment and health workers. One of the efforts made by researchers to improve maternal knowledge is by providing health education on how to care for dental and oral health.

The results of oral health examinations in the intervention group had a significant difference between oral health examinations before and after the intervention ( $p$ value $=0.000$ and $\alpha=0.05$ ). Changes in the condition of the results of oral health examination with the difference between the oral health check before and after treatment is 0.66. Dental and oral care by parents at home can improve dental and oral health. Parents stated that they were happy to be included in this research activity, because the children were motivated to treat their teeth and mouth regularly, especially at 1 month. Parents also said they were happy because the health of the teeth and mouth monitored by the mother teacher made the child more motivated to care for his teeth and mouth. The way to improve dental and oral health is that parents must pay attention to children's behavior related to dental and oral health and children's eating patterns by consuming foods that do not damage dental and oral health [10]. Food is very influential on teeth and mouth. Foods that are tooth-cleaning such as apples, guava and jicama. Sweet and soft foods that are easily attached to the teeth are very damaging to teeth such as candy and chocolate. Oral hygiene ranks first as the cause of caries [7]

In the control group there was a significant difference between the results of the oral examination before and after the intervention ( $\mathrm{p}$ value $=0.037$ and $\alpha=0.05$ ). The difference between the results of oral examination before and after treatment is 0.28 . Students in the control group might try to treat their teeth and mouth because the researchers said they would do dental and oral health checks one month later. Students are also motivated to take care of their teeth and mouth because researchers will come again one month later.

The factors that most influence changes in knowledge, attitudes and oral health are age. School age is able to absorb the information provided related to dental and oral care. Good absorption of information by children is able to change the understanding of attitudes and skills how to care for teeth and mouth properly. The impact of this understanding can improve dental and oral health status in children.

\section{CONCLUSION}

There is an effect of health education on how to care for teeth and mouth for knowledge, attitudes and skills and dental and oral health status in school-age children. And there is a significant difference in knowledge, attitudes and skills as well as dental and oral health status of school-age children before and after health education was carried out in the intervention group ( $p$ value $=0.000$ to $p$ value $=0.002$ and $\alpha=0.05$ ). 3. There is a significant difference in attitudes and skills and oral health status of school-age children before and after health education was carried out in the control group ( $\mathrm{p}$ value $=0.000$ to $\mathrm{p}$ value $=0.002$ and $\alpha=0.05$ ). The increase in the value of knowledge, attitudes, skills, dental and oral health status is better in the intervention group than in the control group and factors that most influence changes in knowledge, attitudes and oral health status are age factors.

\section{ACKNOWLEDGEMENT}

This study has been approved ethical clearance from Health Polytechnics Ministry of health Jakarta III ethics committee. Thanks to Director of Health Polytechnics Ministry of health Jakarta III for funding this research, Head of community Health Center, Cipayung Jakarta for research place

\section{REFERENCES}

[1] Kemenkes RI Ministry of Health.Technical Guidelines for Screening Health and Periodic Examination in Primary and Secondary Education Units. Jakarta: Kemenkes RI. 2015.

[2] Riskesdas. Indonesian Health Profile. Jakarta: RI Ministry of Health. 2013.

[3] Indonesian Ministry of Health. PHBS in Schools. Jakarta: RI Ministry of Health. 2011.

[4] Sasmita, I. Overview of Effects of Herbal Toothpaste on Decreasing Plaque Index. www.unpad.ac.id. 2012.

[5] Worototitjan, I., Mintjelungan, CN., And Gunawan, P. Experiences in Dental Caries and Eating and Drinking Patterns in Elementary School Children in Kiawi Village North Kowangkong District. Journal.e-Gigi.Vol.1.(1). 2013.

[6] Alhamda, S. Dental and Oral Health Status with Dental Caries Status. Public Medical News.Vol.27.(1). 2011.

[7] Wati, R. Effect of Providing PHBS Counseling on Hand Washing on Knowledge and Hand Washing Attitudes in Grade V Students at Surakarta Bulukantil Elementary School. www.digilib.uns.ac.id. 2011.

[8] Budisuari, M.A., Oktarina and Mikrajab, M.A. Relationship Between Diet and Tooth Brushing Habits with 
Dental and Oral Health in Indonesia. Health System Research Bulletin .Vol 13 (1). 2010.

[9] Rahmawati, I, Hendrartini, J dan Priyanto, A.. Perilaku Kesehatan Gigi dan Mulut pada Anak Sekolah Dasar. Berita Kedokteran Masyarakat: Vol.27 (4). 2011.

[10] Nurhidayat, O., Tunggul, E.P and Wahyono, B. Comparison of Point Power Media with Flipcharts in Increasing Knowledge of Dental and Oral Health. Journal.unnes.ac.id. 2012. 